\title{
Status and Countermeasure Study on Physical Education Teaching Practice
}

\author{
Hui-Jun Jiang \\ College of Physical Education, Hunan First Normal University, Changsha 410205, Hunan, CHINA \\ Xin-Ke Leng \\ College of Physical Education, Hunan University, Changsha 410028, Hunan, CHINA \\ Ji-Sheng Zhang \\ College of Physical Education, Hunan Normal University, Changsha 410308, Hunan, CHINA \\ Xun-Hao Zou \\ College of Physical Education, Hunan First Normal University, Changsha 410205, Hunan, CHINA
}

Received 25 June 2017 - Revised 15 September 2017 • Accepted 1 October 2017

\begin{abstract}
Objective: Teaching practice is an organic part in the process of physical education, is the only way to foster a qualified sports teacher, and a main way to evaluate quality of talents cultivated by universities in an all-round manner. Method: In the paper, literature consultation, questionnaire survey and other methods were applied to investigate on physical education teaching practice status, and countermeasure study was made on problems in practice process and suggestions were put forward accordingly. Process: We conducted exploration from physical education teaching practice's trial teaching, practice preparation, practice school's basic information, practice schedule, practice location and advisors status, intern students' status as well as feedback by the end of practice in accordance with time sequence that intern students participated in teaching practice. Results: We found that there are some problems, such as low satisfaction with trial teaching, single way of intern students' practice units' selection, excessive concentrated practice bases, insufficient intern class hour for intern students, incomplete implementation of probation stage in teaching practice, irresponsible advisors and so on. By doing so, we would provide specific practice experience and theoretical evidence for standardizing and effectively promoting physical education teaching practice, and offer reference data for the progress of Chinese physical education.
\end{abstract}

Keywords: university students, physical education, teaching practice

\section{INTRODUCTION}

As an important part in university physical education's professional teaching plan, physical education teaching practice is not only a basic reflection in helping students to fulfill teaching principle of combining theory with practice, but also an important mean to contribute to realize school current cultivation goals and satisfy social demands (Li, 2005). Through teaching practice, students could realize transformation from professional knowledge to teaching skills and even fulfill teacher transition. At the same time, physical education teaching practice has important tasks as examining quality of universities' talents cultivation and reflecting shortcomings in universities physical education talents cultivation.

(C) Authors. Terms and conditions of Creative Commons Attribution 4.0 International (CC BY 4.0) apply. Correspondence: Xin-Ke Leng, College of Physical Education, Hunan University, Changsha 410028, Hunan, China. xinkeleng@163.com 


\section{Contribution of this paper to the literature}

- In physical education teaching practice, there are some problems, such as low satisfaction with trial teaching, single way of intern students' practice units' selection, excessive concentrated practice bases, insufficient intern class hour for intern students, incomplete implementation of probation stage in teaching practice, irresponsible advisors and so on.

- From analysis of data in Table 25 regarding investigation on physical education teaching practice influence factors, we found common guidance management of advisors and practice schools, and emphasis of school leaders respectively ranked in the first and second, with a proportion of over $50 \%$. Construction situation of practice base and arrangement of teaching practice time and cycle ranked the third, and the fourth, respectively.

Physical education teaching practice is of important significances in physical education. It provides examination platform of knowledge and skills for students majoring in physical education of universities, and is able to provide theoretical evidence and suggestions for the development and reform of physical education major (Zhang \& Peng, 2017). By consulting information and investigation, we found that there were little studies on physical education teaching practice. Thus, the writer supposes that the paper' investigation on physical education teaching practice is of great realistic significances.

\section{Research Background and Status}

Concept of teaching practice is complicated, and that by far has no unified demarcation in academic cycle. There is a rather complete annotation of teaching practice in works, such as Xiangru Li etc. "Chinese universities physical education teaching practice reform study" (Li \& Qu, 2005). Wei Zhang and Zhaoqing Meng "Physical education teaching practice", "Word-ocean", Mingyuan Gu "The comprehensive dictionary of education", Nianhong Zhang chief complied "Encyclopedia of Chinese education", Huangting Zhang chief complied "Education dictionary" (Hu et al., 2017). Gaohou Xu “Teaching Practice". By analyzing opinions in above works, we could conclude that teaching practice is an activity that university intern students go to intern location to engage in education and teaching practice with the common guidance of the intern location and school (Imam et al., 2017).

The conception of physical education teaching practice has also been described by some scholars in their works, such as Chunlu Yu "Guidance and Practice in physical education internship", university textbook "Physical education teaching practice guidance" (Li et al., 2001). Qiming Wang "Physical education teaching practice". By analyzing their description, we could conclude that physical education teaching practice referred to an important part in university physical education professional teaching plan, and a link to promote students' comprehensive ability in the way that transforming students' personal theoretical knowledge to practical ability and shift their psychological state towards teachers by teaching practice.

At present, some domestic experts and scholars have also made rather comprehensive study on physical education teaching practice through extensive research methods and from various perspectives. In the study, they made investigation, made analysis, made summary and put forward new opinions and thinking as well as new challenges in teaching practice process targeted at current undergraduate practice status. There were rather mature description in some people's works, for instance, Chunlu Yu "Guidance and Practice in physical education internship", university textbook "Physical education teaching practice guidance", Qiming Wang "Physical education teaching practice" (Shi et al., 2004).

From physical education teaching practice's characteristics, it has own particularities-wider coverage, which not only remains in class but moreover is practice on entire school's sports work, including intern head teacher, sports teaching activity, sports training and other works $(\mathrm{Xu}, 2003)$. Siyong Xia thought that there were four characteristics in teaching practice, such as i) practicalness; ii) comprehensiveness; iii) normalization; iv) guidance. As Chinese university class teaching has improved systematically, it has some new exploration in theory and practice of teaching practice. However, on a whole, physical education has still defects and shortcomings, such 
as short and concentrated practice duration, single form, ineffective practice guidance, which is bad for development of intern students' personality.

Society has attached high attentions by far to problems in teaching practice, and many Chinese experts and scholars have carried out rather mature study on physical education teaching practice mode, such as Xiaoju Shi "Research and practice in university physical education teaching practice mode". Cangfan Cheng "Discussing on reform in physical education teaching practice mode". Chunlu $\mathrm{Yu}$ "Research on physical education teaching practice mode". Cuixiang Dong and Yuejin Li "Initial exploration on Normal colleges' physical education teaching practice mode and management countermeasure". All have analyzed and explored current Chinese physical education teaching practice mode, and put forward teaching practice mode in multi-form, multi-channel and multiplan. Jie Zheng "Advanced normal colleges' teaching practice mode comparative study and suggestions", Xiangchao Ling, Shumao Lan" Discussing on university physical education "Rolling" teaching practice", Ruxi Li put forward "Three in one" teaching practice mode. These researches have provided specific practical experience and theoretical evidence for universities' physical education teaching practice and constructive opinions and suggestions for development of Chinese physical education from physical education mode. Yao Luo "Contrastive research on Chinese and American normal college teaching practice", Chaoying Wang "Advanced university physical education internship's theory and practice", Fenghua Miao and Qiaomei Zhou "Teaching practice mode reform and advanced normal colleges' connotative development". These researches thought that by far main Chinese teaching practice ways were monocyclic teaching practice mode, dicycle teaching practice, "Three in one" teaching practice mode and open practice way;Replacement teaching, "national training plan" supporting teaching practice, concentrated teaching practice and scattered teaching practice and so on. Qiang Feng"Initial discussion on teaching practice evaluation on students major in physical education of advanced normal colleges" thought that advisors were difficult to make comprehensive, fair and correct evaluation due to lack of quantitative evaluation criterion, causing their evaluation on students' teaching practice being excessive subjective and arbitrary that affected students' positivity in teaching practice. Qiang Feng “Initial discussion on teaching practice evaluation on students major in physical education of advanced normal colleges", Bingkang Dang "Study on physical education teaching practice performance evaluation system", Jianqiu Jin etc. "Research on reform of teaching practice in physical education major". Shiyan Li, Zhanqi He and Yanhong Su "Construction and study on physical education teaching practice performance evaluation indicator system". Zhi Gao, Jian Liu and Wang Yao "Construction and empirical study on physical education teaching practice performance indicator system". Yu Wang "Research on Hebei Normal University's physical education students' replacement teaching performance evaluation indicator system". Yu Hao "Shanghai Normal University physical education teaching practice status investigation and mode reform study". All have presented their unique cognition and thoughts on Chinese physical education teaching practice evaluation, and also put forward opinions and suggestions on teaching practice evaluation. Anegleyce Teodoro Rodrigues has also explored plans for new teaching practice in "A questão da formação de professores de Educação Física e a concepção de professor enquanto intelectual- reflexivo-transformador".

To sum up, various contents of physical education teaching practice has been constantly perfected with formers' increasingly efforts, concept of teaching practice has been gradually clear, teaching mode has been increasingly optimized, arrangement of practice duration has been increasingly reasonable and teaching practice evaluation has been constantly normalized though. Most of the researches by far are unilateral researches from teaching practice mode, teaching practice status and teaching practice evaluation, lacking of specific and perfect case study. The study thus based on four-month teaching practice, combined with characteristics of physical education major, studied on Grade 2013 physical education teaching practice, which provided practice reference and certain theoretical evidence for physical education major and teaching practice of other departments, and was of theoretical and realistic significances.

\section{Research Purposes and Significances}

Physical education teaching practice is an important part in teaching work of physical education institute. It is an important mean to comprehensive investigate and examine students' physical knowledge, skill, technology and scientific training methods; it is an important path to further carry out professional ideological education and 
training on students as well as improve their teaching ability; it is also an important link to cultivate a qualified sports teacher. It is an important evidence to fully examine students' learning conditions during university, and also a necessary link in comprehensive examination and promotion of students' teaching ability, and moreover the only way for students' shifting towards teachers. Thus, physical education teaching practice is very important for education major, especially for students majoring in physical education. Teaching practice results directly affected students' ability in future teaching.

Physical education teaching practice is of important significances in physical education major, it also provides examination platform of knowledge and skills for students majoring in physical education of universities. At the same time, it could also provide theoretical evidence and suggestions for development and reform of physical education major. By far, with the progress of Chinese society, they have increased requirements in physical education. So that it admits of no delay in strengthening teaching skills of students majoring in physical education of universities thoroughly. Universities ought to make proper perfection in knowledge and skill reserve of students majoring in physical education and strengthen their teaching practical ability in accordance with social demands. This puts forward new requirements for teaching practice of students majoring in physical education of universities. By investigation on physical education teaching practice status, the paper found problems and further put forward constructive suggestions that provided specific practical experiences and theoretical evidence for promoting physical education teaching practice in a standard and effective manner.

\section{RESEARCH OBJECTS AND METHODS}

\section{Research Objects}

Grade 2011 to 2013 undergraduate students majoring in physical education are research objects.

\section{Research Methods}

\section{Literature consultation}

This paper carried out extensive consultation on relevant documents as paper from school library and CNKI, consulted and analyzed them to provide firm theoretical base.

\section{Questionnaire survey}

The research created questionnaire in electronic edition, released it through WeChat, QQ and other network platforms, collected and analyzed data by questionnaire network platform and finally sorted out data using WPS software. It totally released 152 pieces of questionnaire, effectively recovered 152 ones, from which 68 ones answered by pupils and 84 ones answered by schoolgirls. Through analytic investigation on questionnaire data from students in Grade 2011 to 2013, it provided data supports for the paper's research results.

\section{RESULTS AND ANALYSIS}

\section{Investigation on Preparation Status of Probation and Teaching Practice in Physical Education}

\section{Investigation on status of trial teaching in physical education major (can refer to Table 1, Table 2)}

Trial teaching is a kind of teaching practice transition way that has intern students engaged in simulated class teaching through grouping and trial teaching with the guidance of advisors before teaching practice. In this way, the intern students could contact the physical education, practical teaching, know the rules of teaching so that build a good foundation for they completing teaching practice successfully. 
Table 1. Investigation on satisfaction with trial teaching

\begin{tabular}{ccccc}
\hline \multirow{2}{*}{ Content } & \multicolumn{2}{c}{ Yes } & \multicolumn{2}{c}{ No } \\
\cline { 2 - 5 } & Number of people & Percentage & Number of people & Percentage \\
\hline Whether attended trial teaching & 145 & $95.39 \%$ & 7 & $4.61 \%$ \\
\hline Whether performed satisfactory trial teaching & 104 & $68.42 \%$ & 48 & $31.58 \%$ \\
\hline Whether satisfied with trial teaching & 101 & $66.45 \%$ & 51 & $33.55 \%$ \\
\hline
\end{tabular}

Table 2. Investigation on trial teaching schedule and satisfaction

\begin{tabular}{ccc}
\hline Option & Sub-total & Proportion \\
\hline A. Satisfied & 53 & $34.87 \%$ \\
\hline B. Relatively satisfied & 62 & $40.79 \%$ \\
\hline C. General & 30 & $19.74 \%$ \\
\hline D. Not so satisfied & 6 & $3.95 \%$ \\
\hline E. Dissatisfied & 1 & $0.66 \%$ \\
\hline
\end{tabular}

Table 3. Selection of practice school

\begin{tabular}{ccc}
\hline Option & Sub-total & Proportion \\
\hline School allocation & 133 & $87.5 \%$ \\
\hline Independent practice & 17 & $11.18 \%$ \\
\hline Others & 2 & $1.32 \%$ \\
\hline
\end{tabular}

Duration for trial teaching in physical education major is one week that distributed in the sixth term; students would feedback the implementation of trial teaching.

From investigation on intern students' trial teaching participation and satisfaction, we found that though students' participation degree arrived at over $95 \%$ as school focused on the link, data analysis found that students' satisfaction with the link was less than $70 \%$, suggesting that there were more room to promote time and work arrangement in trial teaching. In this link, over 30\% students in total showed their dissatisfaction, suggesting that students' lower satisfaction in the link and they could get limited promotion, which may also reflect in formality trend in the link. We could make promotion from all of the directions.

\section{Investigation on status of practice preparation}

Selective mode of practice school (can refer to Table 3)

Most of intern students majoring in physical education carry out teaching practice by school's unified arrangement; however, by consulting information, affected by employment environment factors nowadays, there common occurs intern students' practice unit arrangement under recommendation of relatives and friends. Whereas there are more intern students taking the initiative to contact with practice unites with the hope of training personal ability through independent practice. Thus, with the progress of society, teaching practice opportunity moves forward multiple has become an inevitable trend. There are more room to strengthen selection of teaching practice ways in the stage of teaching practice.

\section{Practice school basic information}

Practice school is a place that intern students locate in teaching practice stage, rational selection on nature, location and learning stages of the practice school directly related to intern students' adaptation to practice location that would further affect intern students' personal teaching ability promotion (can refer to Table 4, Table 5 and Table 6). The practice school's nature, location and other aspects' factors would exert various impacts on different intern students. Thus, for intern students that engaged in physical education teaching practice, investigation on nature and location of practice school and learning stages of intern students allocated school are of important significances in studying and promoting teaching practice level and quality of intern students majoring in physical education. 
Jiang et al. / Status and Countermeasure of Teaching Practice

Table 4. Nature of practice school

\begin{tabular}{ccc}
\hline Option & Sub-total & Proportion \\
\hline Public school & 87 & $57.24 \%$ \\
\hline Private school & 59 & $38.82 \%$ \\
\hline Others & 6 & $3.95 \%$
\end{tabular}

Table 5. Practice school's location

\begin{tabular}{ccc}
\hline Option & Sub-total & Proportion \\
\hline A. Downtown & 43 & $28.29 \%$ \\
\hline B. Outskirts & 61 & $40.13 \%$ \\
\hline C. Villages and towns under the governance of city & 30 & $19.74 \%$ \\
\hline Other provinces and cities & 18 & $11.84 \%$ \\
\hline
\end{tabular}

Table 6. Learning stages in practice school

\begin{tabular}{ccc}
\hline Option & Sub-total & Proportion \\
\hline Primary school & 34 & $22.37 \%$ \\
\hline Junior high school & 55 & $36.18 \%$ \\
\hline Senior high school & 52 & $34.21 \%$ \\
\hline D.Others & 11 & $7.24 \%$ \\
\hline
\end{tabular}

From comprehensive analysis of Table 4, Table 5 and Table 6, we found that physical education teaching practice school mainly located in public middle school, selection of practice schools is rather single. In addition, Table 5 suggested that practice base mainly located in regions of this city, less in other provinces and cities. Intern students perform teaching practice in nearby regions would cause restricts in students' promotion and be bad for expanding views of them and harmful for their promotion in comprehensive quality.

\section{Teaching Practice Stage}

\section{Investigation on opinions and satisfaction with schedule from intern students engage in postgraduate examination and those not engage}

Through comparing investigation on practice time duration from intern students engage in postgraduate examination and those not engage (can refer to Table 7 and Table 8), we found that the number of intern students though practice long and relative long covered $53.29 \%$ of the total, which goes beyond half the total. However, comparing intern students that engage in postgraduate examination and those not engage, among the formers, there were 17 people thought practice long, and 35 ones thought it longer, all above half in this item, whereas 43.43 $\%$ intern students thought teaching practice time moderate. from which the number of students don't engage in postgraduate examination accounted for $92.4 \%$, therefore most intern students that engaged in postgraduate examination thought time arrange not reasonable, from which only 5 thought practice time shorter that accounted for $3.29 \%$ of the total. With regard to this, from data in comprehensive analytic Table 8 , there shows serious polarization in attitude towards practice duration from intern students engage in postgraduate examination, which was mainly shown in the item of long, longer and shorter. By comparing, students that don't engage in postgraduate examination has higher satisfaction with time arrangement, those thought time arrangement reasonable covered high ratio. 
Table 7. Investigation on time duration opinions from intern students engage and don't engage in postgraduate examination

\begin{tabular}{ccccccc}
\hline \multirow{2}{*}{ Option } & \multirow{2}{*}{$\begin{array}{c}\text { Sub- } \\
\text { total }\end{array}$} & Proportion & \multicolumn{2}{c}{$\begin{array}{c}\text { Engage in postgraduate } \\
\text { examination (two months) }\end{array}$} & \multicolumn{2}{c}{$\begin{array}{c}\text { Non-engagement in postgraduate } \\
\text { examination (four months) }\end{array}$} \\
\cline { 3 - 7 } & & Number of people & Percentage & Number of people & Percentage \\
\hline A. Long & 29 & $19.08 \%$ & 17 & $27.4 \%$ & 12 & $13.3 \%$ \\
\hline B. Relatively long & 52 & $34.21 \%$ & 35 & $56.5 \%$ & 17 & $67.9 \%$ \\
\hline C. Appropriate & 66 & $43.42 \%$ & 5 & $8.1 \%$ & 61 & 0 \\
\hline D. Relatively short & 5 & $3.29 \%$ & 5 & $8.1 \%$ & 0 & 0 \\
\hline E. Short & 0 & $0 \%$ & 0 & 0 & 0 & 0 \\
\hline
\end{tabular}

Table 8. Investigation on satisfaction with practice time arrangement

\begin{tabular}{ccccccc}
\hline \multirow{2}{*}{ Option } & \multirow{2}{*}{$\begin{array}{c}\text { Sub- } \\
\text { total }\end{array}$} & Proportion & \multicolumn{2}{c}{$\begin{array}{c}\text { Engage in postgraduate } \\
\text { examination }\end{array}$} & $\begin{array}{c}\text { Non-engagement in postgraduate } \\
\text { examination }\end{array}$ \\
\cline { 3 - 7 } & & & Number of people & Percentage & Number of people & Percentage \\
\hline A. Reasonable & 72 & $47.37 \%$ & 20 & $28.6 \%$ & 50 & $69.4 \%$ \\
\hline B. General & 70 & $46.05 \%$ & 47 & $67.1 \%$ & 23 & $32.9 \%$ \\
\hline C. Not reasonable & 10 & $6.58 \%$ & 10 & $100 \%$ & 0 & 0 \\
\hline
\end{tabular}

Table 9. Investigation on leading teachers and advisors' conditions

\begin{tabular}{ccccc}
\hline \multirow{2}{*}{ Content } & \multicolumn{2}{c}{ Yes } & \multicolumn{2}{c}{ No } \\
\cline { 2 - 5 } & Number of people & Percentage & Number of people & Percentage \\
\hline Whether has leading teachers in this specialty & 34 & $22.37 \%$ & 118 & $77.63 \%$ \\
\hline Whether has guidance with competent advisors & 105 & $69.08 \%$ & 48 & $30.92 \%$ \\
\hline
\end{tabular}

From data in Table 8, practice time satisfaction investigation reflected that 72 people thought it reasonable, accounting for $47.37 \%$. Among them, there were 20 intern students engage in postgraduate examination, accounting for $28.6 \%$; while 50 don't engage in postgraduate examinations, accounting for $69.4 \%$, whereas 70 intern students thought it normal, accounting for $46.05 \%$ of the total, from which 47 were students engage in postgraduate examination, accounting for $67.1 \%$, and 23 were students don't engage in postgraduate examination, accounting for $32.9 \%$. And there were 10 thought it not reasonable, who engages in postgraduate examination. To synthesize data in Table 8, we can conclude that on a whole, there showed low satisfaction with physical education teaching practice time arrangement, which were mainly from intern students that engage in postgraduate examination.

Combine analysis in Table 7 and Table 8, we can conclude that intern students have shown low satisfaction with time arrangement of teaching practice, from which are mainly intern students engage in postgraduate examination. So we should further arrange these students' teaching practice time more reasonable.

\section{Investigation on leading teachers and advisors' conditions}

Analyze table's data (can refer to Table 9), there were only 34 intern students had leading teachers in this specialty, only accounting for $22.37 \%$ of the total. This also reflected shortage of teachers in physical education teaching practice. In addition, over $30 \%$ intern students thought advisors incompetent. This was also a reflection of implementing practice base not thoroughly.

\section{Investigation on intern students' probation stage}

Probation stage is an indispensible part in the process of teaching practice. In this stage, intern students went into practice base to observe and emulate teacher's class to learn their teaching skills, technology and organization way, and then carry out practice and feedback to improve personal ability. On the other hand, probation stage could be a warm-up period for intern students and teaching objects, enabling intern students to initially know basic learning conditions of teaching objects, which is conductive to fast integrate intern students into teaching objects and promote practice efficiency. 
Jiang et al. / Status and Countermeasure of Teaching Practice

Table 10. Whether goes through probation stage

\begin{tabular}{ccc}
\hline Option & Sub-total & Proportion \\
\hline A. Yes & 102 & $67.11 \%$ \\
\hline B. No & 50 & $32.89 \%$ \\
\hline
\end{tabular}

Table 11. Intern students' weekly class hours investigation

\begin{tabular}{ccc}
\hline Option & Sub-total & Proportion \\
\hline A. $1-5$ lessons & 46 & $30.26 \%$ \\
\hline B. $6-10$ lessons & 56 & $36.84 \%$ \\
\hline C. $10-15$ lessons & 41 & $26.97 \%$ \\
\hline D. $16-20$ lessons & 8 & $5.26 \%$ \\
\hline Over 20 lessons & 1 & $0.66 \%$ \\
\hline
\end{tabular}

Table 12. Whether submits teaching plan

\begin{tabular}{ccc}
\hline & Sub-total & Proportion \\
\hline A. Yes & 111 & $73.03 \%$ \\
\hline B. No & 41 & $26.97 \%$ \\
\hline
\end{tabular}

Practice school is intern's internship phase of colleges and universities, the nature of the practice school, location selection, and reasonable period directly influences the intern can adapt to the status quo of ShiXiDian, thus affecting the trainee can improve their teaching ability. The nature, location and other factors of the practice school have different effects on different interns. Professional sports education practice, therefore, to investigate the interns, the investigation of the nature of the practice school, location, and interns in school period, to study to improve sports education professional level and quality of interns internship has important significance.

Table 10 reflected that probation problem in physical education teaching practice mainly lied in not thoroughly implementation. There are 50 intern students haven't experiences probation stage, accounting for $32.89 \%$ of the total. As an indispensable link in teaching practice, probation stage is of very important significance, not thoroughly, implementation would directly affect practice efficiency. Therefore, efforts should be made to reinforce implementation of probation in teaching practice. Practice school is a place that intern students locate in teaching practice stage, rational selection on nature, location and learning stages of the practice school directly related to intern students' adaptation to practice location that would further affect intern students' personal teaching ability promotion. The practice school's nature, location and other aspects' factors would exert various impacts on different intern students. Thus, for intern students majoring physical education under investigation, making investigation on nature and location of practice school and learning stages of intern students allocated school are of important significances in studying and promoting teaching practice level and quality of intern students majoring in physical education.

\section{Investigation on intern students' weekly class hour arrangement status}

Amount of intern students' class hours could reach proper requirement is a criterion to check whether the students could effectively train their teaching ability. Table $\mathbf{1 1}$ suggested that physical education intern students with one to ten weekly class hours reached 102 , accounting for $67.1 \%$. Actually, intern students daily class hour is two lessons or below, and their weekly class hours are little.

\section{Investigation on implementation of teaching plan}

In teaching practice, teaching plan is a reflection of intern students' pre-class preparation and design of class, excellent teaching plans would be conductive to intern students' better fulfillment in teaching tasks. Table 12 data suggested that over a quarter intern students haven't submitted teaching plans, which exerts great impacts on classroom teaching in teaching practice, and was bad for intern students' better designing and fulfilling classroom teaching in practical teaching. 
Table 13. Investigation on intern students' practice tasks

\begin{tabular}{ccc} 
Option & Sub-total & Proportion \\
\hline A. Indoor physical education course teaching & 74 & $48.68 \%$ \\
\hline B. Outdoor physical education course teaching & 148 & $97.4 \%$ \\
\hline C. Head teacher work & 50 & $32.9 \%$ \\
\hline D. Second class & 59 & $38.82 \%$ \\
\hline E. Exercising in training team & 53 & 35 \\
\hline F. Sports competition organization, arrangement and referee & 14 & $23.03 \%$ \\
\hline G. Sports scientific research work & $9.21 \%$ \\
\hline
\end{tabular}

\section{Investigation on intern students' practice tasks}

Physical education teaching practice is of important significances in physical education major, it also provides examination platform of knowledge and skills for students majoring in physical education of universities. At the same time, it could also provide theoretical evidence and suggestions for development and reform of physical education major. By far, with the progress of Chinese society, they have increased requirements in physical education. So that it admits of no delay in strengthening teaching skills of students majoring in physical education of universities thoroughly. Universities ought to make proper perfection in knowledge and skill reserve of students majoring in physical education and strengthen their teaching practical ability in accordance with social demands. This puts forward new requirements for teaching practice of students majoring in physical education of universities. By investigation on physical education teaching practice status, the paper found problems and further put forward constructive suggestions that provided specific practical experiences and theoretical evidence for promoting physical education teaching practice in a standard and effective manner.

Intern students' task in practice location is the main part of the students' teaching practice, reasonable practice tasks would be conductive to better improve intern students' various ability. In physical education teaching practice, intern students' task mainly reflects in outdoor physical education course that reached $97.4 \%$, which is far higher than other projects. Indoor sports courses teaching is much less by comparison, only $48.68 \%$ less than half of the total. The number of people in other projects and their proportion of the totality were under $40 \%$, reflecting the task in the education practice link is relatively single, and cannot satisfy the comprehensive development of the intern students. As shown in Table 13.

\section{Exchange between intern students, advisors, and feedback}

16)

Investigation on exchange between intern students and advisors (can refer to Table 14, Table 15 and Table

Intern student is the main part of teaching practice, the reasonable practice tasks would help them to better improve their various ability. Effective communication between intern students and advisors would be conductive to better fulfill practice task and improve level of teaching practice. 
Jiang et al. / Status and Countermeasure of Teaching Practice

Table 14. Whether carry out after-class summary and exchange with advisors

\begin{tabular}{ccc}
\hline Option & Sub-total & Proportion \\
\hline A. Yes & 110 & $72.37 \%$ \\
\hline B. No & 42 & $27.63 \%$ \\
\hline
\end{tabular}

Table 15. Guiding frequency of advisors

\begin{tabular}{ccc}
\hline Option & Sub-total & Proportion \\
\hline Guiding once per class & 30 & $19.74 \%$ \\
\hline Guiding once per day & 55 & $36.18 \%$ \\
\hline Guiding once per week & 49 & $32.24 \%$ \\
\hline Guiding once per month & 12 & $7.89 \%$ \\
\hline Never guide & 5 & $3.29 \%$ \\
\hline Others & 1 & $0.66 \%$ \\
\hline
\end{tabular}

Table 16. Investigation on advisors' guiding attitude

\begin{tabular}{ccc}
\hline Option & Sub-total & Proportion \\
\hline Serious & 43 & $28.29 \%$ \\
\hline Relatively serious & 68 & $44.74 \%$ \\
\hline General & 28 & $18.42 \%$ \\
\hline Not so serious & 11 & $7.24 \%$ \\
\hline Halfhearted & 2 & $1.32 \%$ \\
\hline
\end{tabular}

Table 14 data suggested there are certain problems between intern students and advisors. From investigation on after-class summary and exchange between intern students and advisors, we found over a quarter intern students haven't engaged in the link. This reflected there were shortcomings in exchange between intern students and advisors in practice stage.

Effective communication between intern students and advisors would be conductive to better fulfill practice task and also improve level of teaching practice.

Investigation data of advisors guiding frequency on students shown that although most of the advisor had a reasonable guiding frequency, there still occurred little non-guiding or less guiding times.

In investigation on advisors' guiding attitude towards intern students, there are only 43 advisors with serious attitude, accounting for $28.29 \%$ of the total, whereas 68 ones with relatively serious attitude, accounting for $44.74 \%$ of the total. The proportion of advisors with serious and relative serious attitude reaches $73.01 \%$ in all. On a whole, intern students have higher satisfaction with advisor's guiding attitude, while the advisor could make further improvement. Total number of people that show general, not so serious and not serious is 41 , accounting for $27 \%$ of the total. Guiding attitude of advisors is crucial for intern students' teaching practice. In case those advisors are halfhearted, teaching practice quality would be affected directly, so would intern students' positivity in teaching practice.

The investigation on communication way between intern students and advisors as well as leading teachers (can refer to Table 17) used Table data to reflect problems among their communication. From investigation on afterclass brief summary and exchange between intern students and advisors, we found over a quarter of intern students didn't engage in the stage, suggesting shortcomings between intern students and advisors' communication in teaching practice. Effective exchange between intern students and advisors would be conductive to better fulfilling of practice tasks and promote level of practice. 
Table 17. Investigation on communication ways among intern students, advisors and leading teachers

\begin{tabular}{ccccc}
\hline \multirow{2}{*}{ Option } & \multicolumn{2}{c}{ Advisors } & \multicolumn{2}{c}{ Leading teachers } \\
\cline { 2 - 5 } & Number of people & Percentage & Number of people & Percentage \\
\hline A. Face to face communication & 53 & $34.87 \%$ & 58 & $38.16 \%$ \\
\hline B. Telephone communication & 59 & $38.82 \%$ & 42 & $27.63 \%$ \\
\hline C. Network communication & 25 & $16.45 \%$ & 39 & $25.66 \%$ \\
\hline D. Get involved in all above ways. & 15 & $9.87 \%$ & 13 & $8.55 \%$ \\
\hline
\end{tabular}

Table 18. Investigation on implementation of open class

\begin{tabular}{ccc}
\hline Option & Sub-total & Proporition \\
\hline A. Yes & 103 & $67.76 \%$ \\
\hline B. No & 49 & $32.24 \%$ \\
\hline
\end{tabular}

Table 19. Composition of teaching practice evaluation

\begin{tabular}{ccc}
\hline Option & Sub-total & Proportion \\
\hline Directly evaluated by school leading teachers & 27 & $17.76 \%$ \\
\hline Common evaluated by advisors and school leading teachers & 66 & $43.42 \%$ \\
\hline Common evaluated by advisors, school leading teachers and intern student members & 53 & $34.87 \%$ \\
\hline D. No evaluation & 6 & $3.95 \%$ \\
\hline
\end{tabular}

From data in Table, communication among intern students, advisors and leading teachers in physical education teaching practice were mainly private communication, lacking of official teacher-student communication platform. In teaching practice, the effective teacher-student communication is precondition and base for success completing practice, and a reasonable and effective teacher-student communication platform is conductive to implement teaching practice. Efforts should be made in the regard.

Intern students' open class teaching task is an important mean to examine their efficacy in practice stage, and also an important component in teaching practice evaluation on intern students. It is intuitive reflection of the intern students' practice efficiency. From feedback of intern students in Table 18, the ones that haven't gone through open class teaching have arrived at $32.24 \%$. This reflects there is a huge loophole in teaching practice examination; efforts should be made to implement teaching practice.

\section{Teaching practice evaluation}

Teaching practice evaluation is an important task in the ending stage of teaching practice. On one hand, it is objective evaluation on intern students' performance and progress in practice stage; on the other hand, it is recognition and encouragement on intern students' practical work, and is of great help in promoting intern students' work positivity. In the process of the evaluation, it bases on practice advisor and leading teachers' evaluation and in a single way. Selection of excellent intern students is an important result in teaching practice evaluation. The school should encourage and affirm excellent intern students that had good performance during practice. Evaluation on excellent intern students were fulfilled using data in Table 19 and Table 20. In teaching practice, effective exchange between teacher and students is precondition and foundation for the success completion of teaching practice, and a reasonable effective teacher-students exchange platform is conductive to facilitate implementation of practical work that should be strengthened.

From analysis of data, evaluation on excellent intern students mainly based on scores of leading teachers and supplemented with other items. In actual operation process, only school leading teacher decided the evaluation results, which was bad for objective evaluation on intern students. 
Jiang et al. / Status and Countermeasure of Teaching Practice

Table 20. Investigation on excellent intern students' evaluation

\begin{tabular}{ccc}
\hline Option & Sub-total & Proportion \\
\hline Advisors' practice scoring & 60 & $39.47 \%$ \\
\hline School leading teachers practice scoring & 104 & $68.42 \%$ \\
\hline C Practice open class scoring & 64 & $42.11 \%$ \\
\hline Trial teaching teachers' scoring & 46 & $30.26 \%$ \\
\hline E. Others & 5 & $3.29 \%$ \\
\hline
\end{tabular}

Table 21. whether has gains through teaching practice

\begin{tabular}{ccc}
\hline Option & Sub-total & Proportion \\
\hline A. Yes & 115 & $75.66 \%$ \\
\hline B. No & 37 & $24.34 \%$ \\
\hline
\end{tabular}

Table 22. Investigation on intern students' teaching skills promotion during teaching practice process

\begin{tabular}{ccc}
\hline Option & Sub-total & Proportion \\
\hline A. Teaching design ability & 69 & $45.39 \%$ \\
\hline B. Ability of observing and evaluation lesson & 93 & $61.18 \%$ \\
\hline C. Teaching plan written ability & 78 & $51.32 \%$ \\
\hline D. Specialized sports skills & 60 & $39.47 \%$ \\
\hline
\end{tabular}

Teaching Practice Summary

\section{Feedback investigation on teaching practice gains}

Through Table 21 data, intern students have shown promotion through practice, over $75 \%$ of them thought they had gains in the stage.

By Table 22, we found that intern students' class observation, evaluation ability, and teaching plan writing ability and teaching design ability respective ranked the first, second and third. That's because intern students should experience most on these three items during teaching practice. However, from feedback analysis of intern students, there showed little proportion of intern students' specialized sports skills' promotion in teaching practice. That's because intern students were newly required to be all-round practice teachers in social development, they should not only adept in their professional skills but also master other events. This was new requirement as "specialized and versatile" for intern students. But in teaching practice, we found there were differences between major and practice location's teaching or teaching contents in practice locations were neglected in university courses and even no corresponding course. Thus, most of the intern students have shown no significant promotion in specialized sports skills after teaching practice.

By investigation, we found that "enhance physical education ability" ranked the top in the gains of intern students' teaching practice; and "improve coaching ability in extracurricular physical exercises" ranked the second, while "Increase self-confidence and promote social communication ability" ranked the third; "Promote ability of leading extracurricular sports training" ranked the fourth. and "Foster sports competition organization, arrangement and referee ability" ranked the fifth, and the other three came last with similar proportion that generally lower than $20 \%$, as shown in Table 23 . 
Table 23. Investigation on gains through teaching practice

\begin{tabular}{ccc}
\hline Option & Sub-total & Proportion \\
\hline Increase self-confidence and promote social communication ability & 59 & $38.82 \%$ \\
\hline Enhance physical education teaching ability & 88 & $57.89 \%$ \\
\hline Improve coaching ability in extracurricular physical exercises & 74 & $48.68 \%$ \\
\hline Promote ability of leading extracurricular sports training & 58 & $38.16 \%$ \\
\hline Foster sports competition organization, arrangement and referee ability & 56 & $36.84 \%$ \\
\hline Help themselves to transform into would-be teachers & 27 & $17.76 \%$ \\
\hline Cultivate ability in teaching and scientific researching & 23 & $15.13 \%$ \\
\hline $\begin{array}{c}\text { Could correctly understand themselves, objectively evaluate their works and } \\
\text { promote physical health test ability }\end{array}$ & 23 & $15.13 \%$ \\
\hline
\end{tabular}

Table 24. Investigation on teaching practice problem feedback

\begin{tabular}{ccc}
\hline Option & Sub-total & Proportion \\
\hline $\begin{array}{c}\text { Insufficient docking between university learning content and practical } \\
\text { teaching in primary and secondary school }\end{array}$ & 71 & $46.71 \%$ \\
\hline Shortage of personal practical teaching ability and experience & 82 & $53.95 \%$ \\
\hline Practice school's students low recognition, disobey classroom discipline & 78 & $51.32 \%$ \\
\hline Not enough sites and equipment in practice school & 55 & $36.18 \%$ \\
\hline Be weak in arousing students' interests in physical education course & 47 & $30.92 \%$ \\
\hline $\begin{array}{c}\text { Practice school's indifference to physical education and not support } \\
\text { physical education teaching practice }\end{array}$ & 23 & $15.13 \%$ \\
\hline
\end{tabular}

Table 25. Investigation on physical education teaching practice influence factors

\begin{tabular}{ccc}
\hline Option & Sub-total & Proportion \\
\hline A. Arrangement of teaching practice time and cycle & 53 & $34.87 \%$ \\
\hline B. Emphasis of school leaders & 76 & $50 \%$ \\
\hline C. Construction situation of practice base & 74 & $48.68 \%$ \\
\hline D. Common guidance management of advisors and practice schools & 81 & $53.29 \%$ \\
\hline E. Evaluation on teaching practice performance & 44 & $28.95 \%$ \\
\hline F. Teaching practice expenditure & 28 & $18.42 \%$ \\
\hline G. Intern students' emphasis on teaching practice & 10 & $6.58 \%$ \\
\hline
\end{tabular}

\section{Teaching practice problem feedback}

In intern students' problem feedback, insufficient practical teaching ability and short of examination ranked the top that reached $53.95 \%$, and selective rate of low recognition of practice school's students and disobey classroom discipline ranked the second. While the selective rate of practice school ignorance in physical education and sports work was the lowest that were only $15.13 \%$, as shown in Table 24 .

\section{Investigation on teaching practice influence factors}

From analysis of data in Table 25 regarding investigation on physical education teaching practice influence factors, we found common guidance management of advisors and practice schools, and emphasis of school leaders respectively ranked in the first and second, with a proportion of over $50 \%$. Construction situation of practice base and arrangement of teaching practice time and cycle ranked the third, and the fourth, respectively. Relatively, other items' selective rates are lower with little effects.

\section{PROBLEMS AND COUNTERMEASURES}

\section{Problems in Physical Education Teaching Practice}

i) Most of intern students majoring in physical education carry out teaching practice by school's unified arrangement; however, by consulting information, because of comprehensive effects of social various 
factors on employment, there common occurs intern students' practice unit arrangement under recommendation of relatives and friends; whereas there are more intern students taking the initiative to contact with practice unites with the hope of training personal ability through independent practice. Thus, with the progress of society, there are more teaching practice opportunities. In addition, these opportunities move forward multiple is irresistible. However, the school data suggested that there is no significant reflection of diversity in the school teaching practice process.

ii) In the terms of practice base construction, it is mainly concentrated on cities, while less in other provinces, making students to simple take short-term teaching practice within province. This has constraints in promote their ability.

iii) Physical education intern students has fewer class hours every week, the ones with one to five weekly classes accounted for $30.26 \%$, those with six to ten weekly classes accounted for $36.84 \%$, and the proportion of over ten classes was only $32.89 \%$. The general fewer teaching hours may not reach certain density as required.

iv) For trial teaching, though students' participation degree arrived at over $95 \%$ as school focused on the link, data analysis found that students' satisfaction with the link was less than $70 \%$, suggesting that there were more room to promote time and work arrangement in trial teaching. In this link, over $30 \%$ students in total showed their dissatisfaction, suggesting that students' lower satisfaction in the link and they could get limited promotion, which may also reflect in formality trend in the link. All can be promoted.

v) Over 30\% intern students haven't gone through probation, $26.97 \%$ ones haven't submitted teaching plan as no such requirement and over $30 \%$ ones haven't fulfilled open class lecturing. All of these show inappropriate implementation of teaching practice flow in the practice process, which exerts a great impact on intern students' practice fulfillment efficiency, fulfillment and implementation of teaching practice.

vi) Over $30 \%$ intern students haven't guided by advisors, suggesting that basic management construction in practice locations should be strengthened as well as guiding in teaching practice process. By analyzing data, we found that most of the intern students have communicated with school's leading teachers and advisors in the various ways, from which main ways are face-to-face communication, telephone communication and network communication. Guiding frequency of advisors on students is divided into three types, such as once a class, once a day and once a week. But there still occurred no guidance by analyzing. At the same time, in the investigation on satisfaction with advisors' guiding attitude, 25\% has shown in general and not so earnest. The advisors could not timely guide intern students, some even hands-off after sending students to practical school, lacking of taking due responsibilities. Though practical school's advisors basically reach the requirement in education background, some of them hasn't undertake due obligations and some only handle with personal affairs instead of class matters.

vii) Intern students' insufficient teaching practice ability, lacking of experience, lower recognition in practice location have reflected that they should improve their comprehensive ability from the side.

viii) Evaluation on practice performance of intern students majoring in physical education are mainly combination with multiple ways, from which bases on advisors' evaluation and school leading teachers' evaluation. In practice evaluation, it fulfilled mainly by leading teachers' evaluation, practice advisors' evaluation, students' self-evaluation and open course scores, from which trial teaching accounts for the minimum in scores. This leads to problems in the implementation of trial teaching. 
ix) From analysis of data in Table 25 regarding investigation on physical education teaching practice influence factors, we found common guidance management of advisors and practice schools, and emphasis of school leaders respectively ranked in the first and second, with a proportion of over $50 \%$. Construction situation of practice base and arrangement of teaching practice time and cycle ranked the third, and the fourth, respectively. Relatively, other items' selective rates are lower with little effects.

\section{Suggestions to Problems}

\section{Enhance students' comprehensive ability and optimize probation stage}

Targeted at sports class characteristics, school should consciously train students' conscious of teacher in four years' university education; require intern students to carry out orientation training with purpose by referencing sports teacher's ability. It should also strengthen students' ability of combining theory with practice, perform theory education on students and meanwhile integrate teaching practice into education to enable students to have certain ability to dock with actual teaching. The school could also arrange students to emulate and learn through getting into nearby practice base in every academic year and carry out teaching practice with conditions.

\section{Strengthen quality of skill courses and dock with actual teaching conditions in primary and secondary school}

The school should train high professional quality students as specialized and versatile, and meanwhile should foster students with personality and super hard professional skills under the circumstance that they satisfy students' employment demands and open courses in accordance with actual demands and social employment situation. They could strengthen professional course education by perfecting institute curriculum setting, and meanwhile focus on other courses, really implement "specialized and versatile".

\section{Reinforce construction of practice base and encourage students to conduct independent teaching practice}

Teaching practice base actual implementation, base quality, teacher quality and level directly affect practice efficiency and promotion on intern students. Universities should establish long-term cooperative relations with practice base schools, strengthen contact with the school, and reinforce students' positivity and emphasis on teaching practice. At the same time, school should properly expand zones of practice base in accordance with actual situation, establish more non-native practice base to offer intern students more choices. They should encourage students to carry out practice independently and create more practice opportunities.

\section{Establish and perfect network resources platform systematically for ease of exchanging between teachers and students}

Through exchange ways between intern students and advisors, in convenient information transmission era, establishment of a perfect and effective teacher-student exchange platform is an effective channel to make teaching practice perfect.

\section{Lay emphasis on intern students' information feedback, make adjustment positively and advance with times}

When teaching practice ended, school should reinforce emphasis on intern students' information feedback, adopt collective and reasonable methods to summarize and reflect on previous teaching practice process from the perspective of knowledge, ability and quality. Affirm students' advantages, carry forward them while also correct drawbacks, and correct face with defects to make later teaching practice process more targeted. 


\section{ACKNOWLEDGEMENTS}

Adolescents.

An Empirical Study on Chinese Wushu's Promoting Physical Fitness and Social Adaptation of

\section{REFERENCES}

Hu, R., Xiaohui, S., \& Shieh, C. J. (2017). A Study on the Application of Creative Problem Solving Teaching to Statistics Teaching. Eurasia Journal of Mathematics Science and Technology Education, 13(7), 3139-3149. doi:10.12973/eurasia.2017.00708a

Imam, M. H., Tasadduq, I. A., Ahmad, A.-R., \& Aldosari, F. (2017). Obtaining ABET Student Outcome Satisfaction from Course Learning Outcome Data Using Fuzzy Logic. Eurasia Journal of Mathematics Science and Technology Education, 13(7), 3069-3081. doi:10.12973/eurasia.2017.00705a

Li, W. (2005). A Research on the Mixed- up Practice Mode and Multiple Physical Education Teaching Practice Method. Journal of Nanjing Institute of Physical Education, 19(5), 118-120. doi:10.3969/j.issn.10081909.2005.05.039

Li, W. C., \& Qu, R. (2005). Study on the Approaches and Method for All-round Development in Physical Education in College. Journal of Yangling Vocational \& Technical College, 4(2), 60-63. doi:10.3969/j.issn.16719131.2005.02.021

Li, X. R., Zhou, L. Q., \& Gu, W. N. (2001). Study on the reformation about educating practice of specialty of physical education in high school of china. Journal of Guangzhou Physical Education Institute, 21(2), 106-110. doi:10.3969/j.issn.1007-323X.2001.02.029

Shi, X. J., Mei, X. X., \& Zhang, H. J. (2004). Study and Practice of the Teaching Practice Model for P.E. Educational Major. Journal of Fujian Normal University (Philosophy and Social Sciences Edtion), (6), 140-143. doi:10.3969/j.issn.1000-5285.2004.06.026

Xu, W. X. (2003). The Instructional Function of Students in Normal Colleges and Universities. Journal of Northeast Normal University (Social Science), (4), 142-145. doi:10.3969/j.issn.1001-6201.2003.04.022

Zhang, B., \& Peng, P. (2017). Research on the Development of Education Resources for the Internet Plus Universities in the National Health Field. Eurasia Journal of Mathematics Science and Technology Education, 13(8), 50855093. doi:10.12973/eurasia.2017.00984a

\section{http://www.ejmste.com}

